\title{
DESTINATION DAEJEON
}

\section{Afocus on basic research is shifting scientific resources from Seoul to South Korea's central city.}

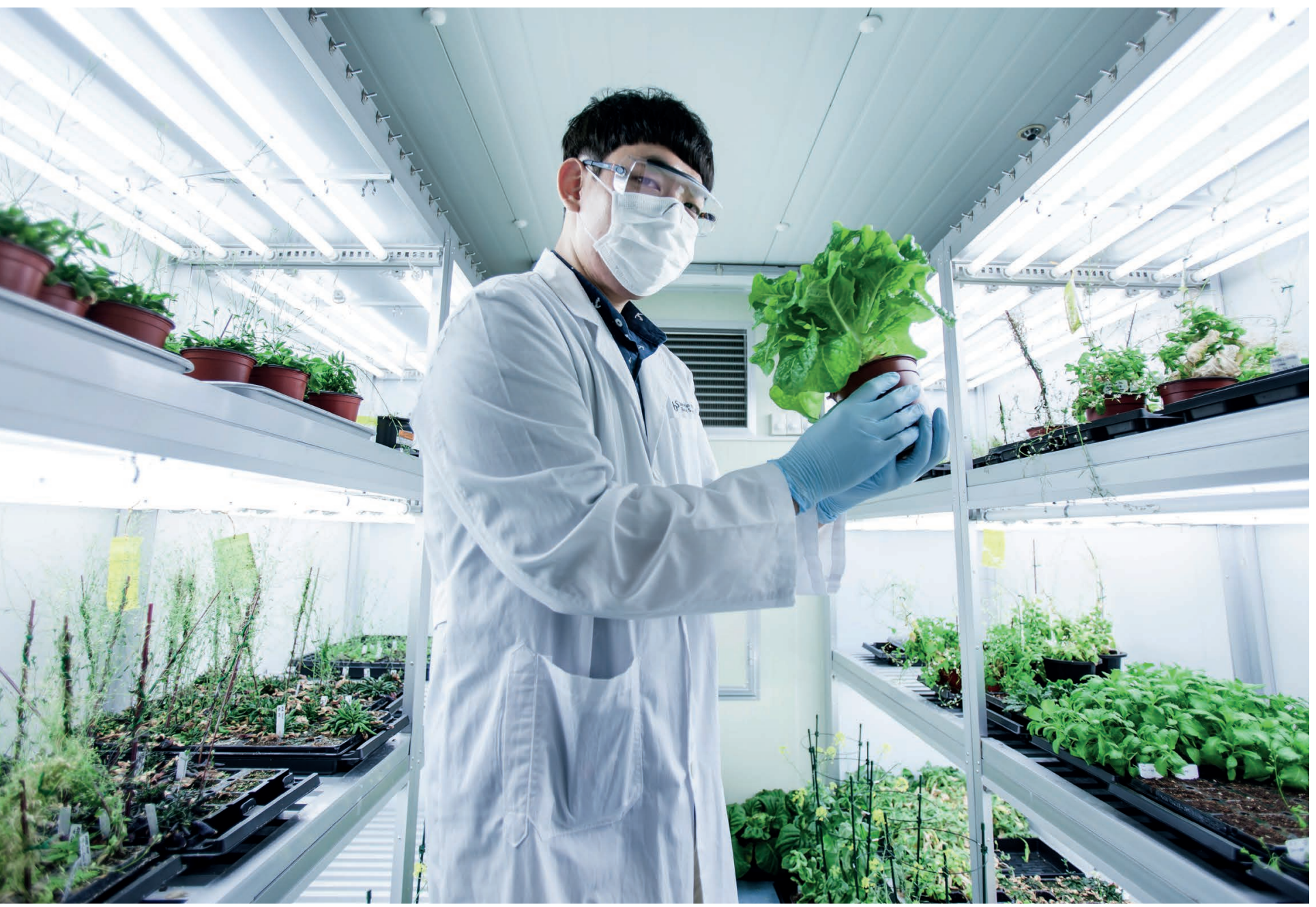

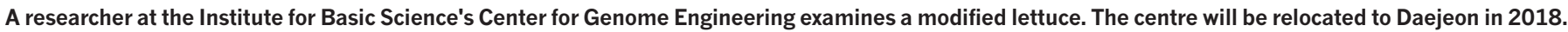

\section{BY MARK ZASTROW}

S outh Korea revealed its scientific prowess on the world stage when it hosted Expo '93, showcasing futuristic technologies like maglev trains and solar cars. The international event was not held in the nation's sprawling, bustling capital of Seoul, but 140 kilometres south, in the city of Daejeon, home to some of the nation's most prominent research institutions. Twenty-five years later, a building is going up on the former expo grounds - the headquarters for the nation's flagship effort in basic research, the Institute for Basic Science (IBS).
IBS reflects Daejeon's prominence in South Korea’s bid to shift its research agenda beyond economic development and focus on more basic science. "It's kind of symbolic," says Yeongduk Kim of the IBS Center for Underground Physics (CUP), which plans to move into the new building in February 2018.

\section{CENTRE STAGE}

Daejeon is located near the geographic centre of the compact country. The city's scientific reputation was forged in the 1960s and 70s, when the nation's president, the dictator, Park Chung-hee, ordered the creation of research centres intended to pull the nation out of its post-war poverty. The focus was squarely on applied research and industrial development. These included the Korea Institute of Science and Technology (KIST), the nation's oldest research institute, and ETRI (Electronics and Telecommunications Research Institute), which pioneered development of the CDMA wireless standard for mobile phones.

As of 2015, there were 24 governmentfunded research institutes in Daejeon, employing more than 10,000 researchers. Most are clustered in the research district called Daedeok Innopolis, along with the Korea Advanced Institute of Science and Technology (KAIST), often called the MIT of Korea, and corporate 
research institutes like LG Chem.

South Korea is now the second-largest investor in research and development as a percentage of GDP, after Israel. It has risen from one of the world's poorest countries in the 1960s to the 11th-largest economy by GDP. This growth has led policymakers to increase investment in basic research, with the hopes of winning the country's first science Nobel Prize.

Created in 2011, IBS was conceived as South Korea's version of Germany's Max Planck Institute and Japan's RIKEN. The institute is at the vanguard of South Korea's struggle to reverse a recent decline in its output of highquality research. The country's contribution to articles in the Nature Index fell from a weighted fractional count (WFC) of 1,184 in 2012 to 1,037 in 2016.

Currently, IBS has 28 centres around the country. Roughly a third will be located in the IBS headquarters in Daejeon — and the building has space for more.

Plans to elevate Daejeon's scientific performance dovetail with government policy to redistribute some of the nation's political and economic activity away from Seoul, even as the capital maintains its global reputation as a hyper-connected tech hub. "Our government has tried to boost other regions," says SungYong Lee, a research fellow at the Korea Institute of Science and Technology Evaluation and Planning (KISTEP) in Seoul.

He says many public and private labs were forced to move to other areas, including South Chungcheong province, west of Daejeon and Busan, the port city in the nation's southeast corner.

Many South Koreans have been only too willing to escape Seoul's crowds, high rent, and worsening air quality. For the past decade, Seoul's population, at 10.2 million, has been stable or declining. Daejeon has about 1.5 million inhabitants.

For Korean researchers who have completed $\mathrm{PhDs}$ or postdoctoral fellowships abroad and are looking to move back to their native country, Daejeon's relaxed vibe and lower cost of living can be attractive, says Jin-Soo Kim, the director of the IBS Center for Genome Engineering, who has recruited many returnees.

\section{LAB MIGRATION}

Statistics from the Nature Index reflect these broader trends. Though Seoul's WFC is more than twice as high as Daejeon's, that gap has narrowed in recent years largely due to Seoul's decline in output by $19.8 \%$. Daejeon's output has remained relatively stable.

A small but significant portion of Daejeon's output can be attributed to researchers leaving Seoul for IBS headquarters in Daejeon intended to host a variety of centres to promote the exchange of ideas and cross-disciplinary collaborations. And the roughly 10 billion won (US\$8.9 million) annual budgets that it offers each centre - with minimum 10-year

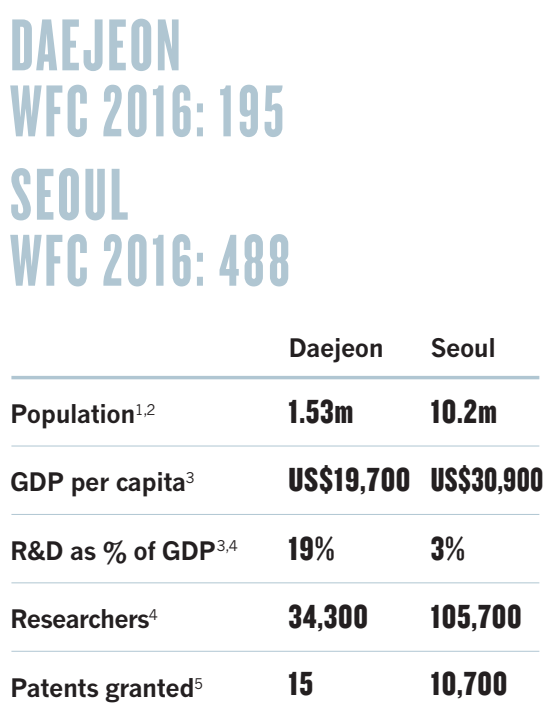

\section{SHARE OF OUTPUT OVER TIME}

City-level contribution to the share of authorship in the Nature Index, measured by the share of weighted fractional count (WFC) for that year, compared to South Korea's share.

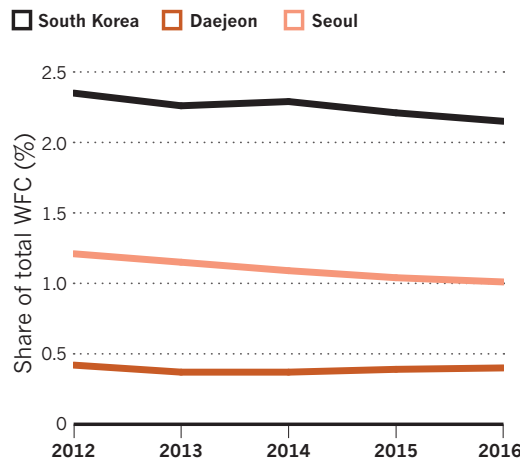

\section{SUBJECT STRENGTHS}

Daejeon and Seoul are strongest in chemistry and the physical sciences, when assessed on their contribution to the share of authorship in the papers included in the Nature Index.

\section{South Korea $\square$ Daejeon $\square$ Seoul \\ Output is based on WFC 2016}

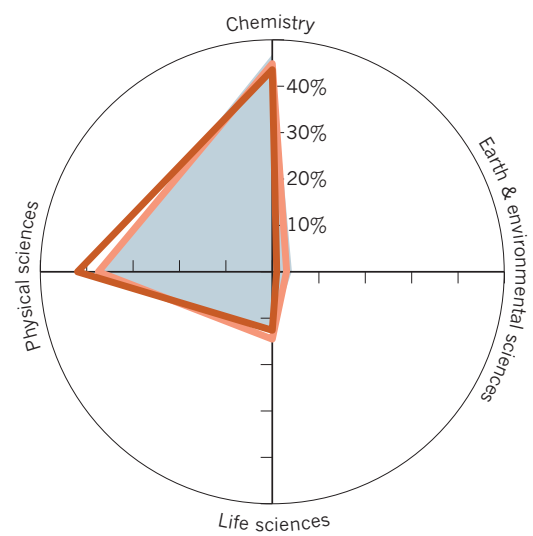

1. Seoul Metropolitan Government (2016) 2. Daejeon Metropolitan City (2016)

mation Service (2016)

(2015) 5. United States Patent and Trademark Office (2015)

\section{IBS EXPANSION}

The IBS, the government's flagship basic science institute, is building facilities across the country, with plans to increase the current 28 centres to 50 .

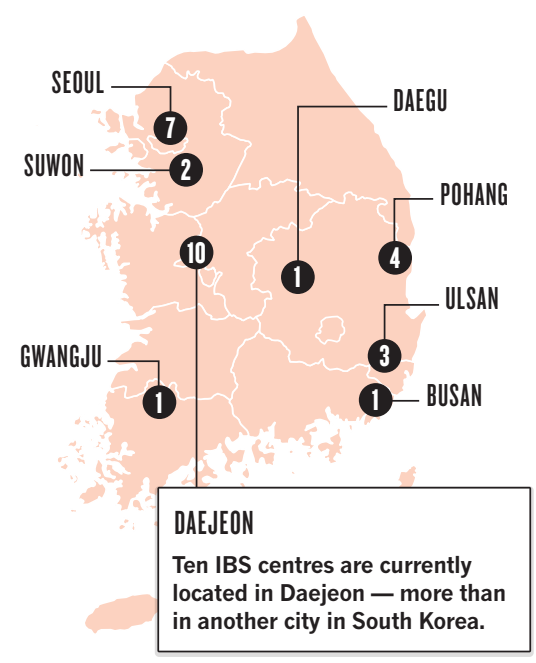

\section{BASIC SCIENCE IN DAEJEON}

The expansion of IBS across the country is having visible benefits for the production of high-quality research. Since 2013, IBS centres located in Daejeon have increased their contribution to the share of authorship in the Nature Index.

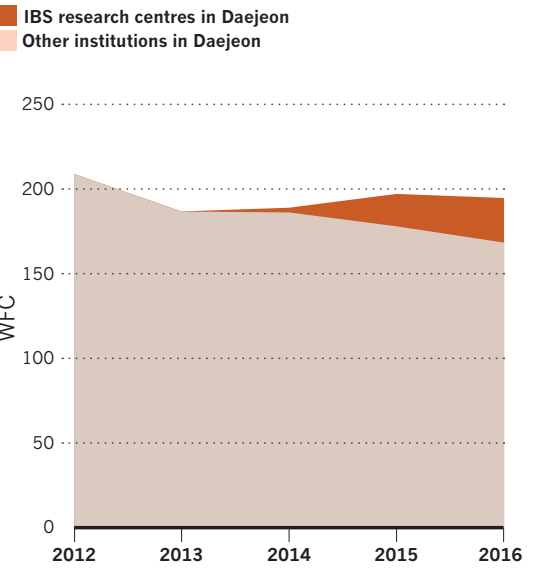

\section{BILATERAL COLLABORATIONS}

The number of bilateral partnerships between an institution in Daejeon and an institution in Seoul has plateaued in recent years.

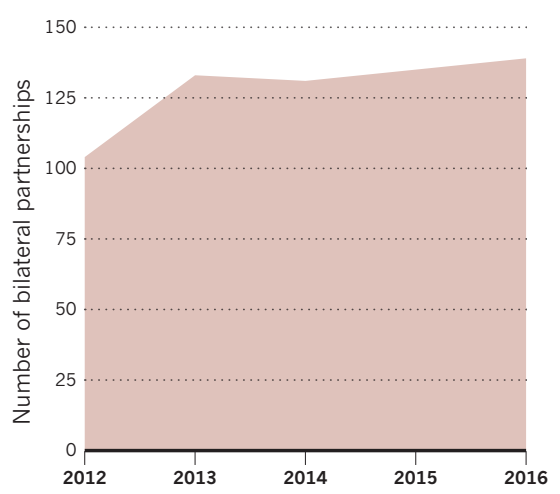


commitments - have proven irresistible to some of South Korea's top scientific talent.

That includes physicist Yeongduk Kim, who was formerly based in Sejong University in Seoul. Kim applied to set up a centre at IBS headquarters.

The move to Daejeon was an easier decision for him, given that the main facility he used while at Sejong - an underground lab with a dark matter detection experiment - is located far from Seoul, anyway. "There was no reason to stick to Seoul. I was happy to move to Daejeon." Most of his team have moved as well, although some have chosen to commute between Daejeon, and Seoul, where their families remain.

Jin-Soo Kim is also set to move from Seoul to Daejeon. Formerly of Seoul National University, Kim and his colleagues have been at the forefront of using the CRISPR gene editing system, collaborating on the first human embryo trials to remove deadly gene mutations, which were published in Nature in August 2017, and carrying out plant and animal trials, including engineering supermuscular pigs for livestock purposes. Now, he's in the process of moving his entire lab of 35 people to IBS in Daejeon.

He concedes that Seoul remains a draw for many of his researchers. "It's a lively, cosmopolitan city." And for Kim's genomics work, Daejeon's lack of medical research institutes is a challenge. "I cannot find good collaborators who are medical doctors in Daejeon," says Kim. He hopes to retain a small laboratory in Seoul to maintain ties with his collaborators, if IBS will approve it.

\section{A NEW RESEARCH ECOSYSTEM}

Boosting resources for genetic medical research is one of the Daejeon government's top research-oriented priorities, says the city's mayor, Kwon Seon-taek. Shifting the country's research agenda towards more basic research can't be left solely to IBS, says Yeongduk Kim, who believes government labs should focus more effort on fundamental investigations.

\section{"THERE WAS NO REASON TOSTICK TO SEOUL. I WAS HAPPY TO MOVE TO DAEJEON:"}

The new cluster of IBS centres emerging in the Daejeon science sector could encourage new collaborations. Since moving to Daejeon, Kim says it has been easier to maintain partnerships with researchers at government labs, like the Korea Research Institute of Standards and Science, with whom he works on lowtemperature technology for particle detectors. "It certainly helps to promote collaborations and make basic science easier than before," says Kim.

Kwon hopes to make Daejeon a popular destination for researchers. His government released a 10-year plan last year that seeks to boost city-level science and technology funding to 200 billion won (US $\$ 178$ million) by 2026, up from 137 billion won in 2016, and recruit 10,000 more research personnel across academia and industry.

Kwon also hopes to encourage science that takes a more society-driven approach, rather than just economic growth. To that end, the city has incorporated citizen feedback directly into some research projects. Officials are using the living lab method, a term that refers to a process of user-led development, usually for socially conscious aims. One such project in Daejeon used internet-connected cameras and sensors to monitor a popular city waterway that often floods during the monsoon season, which citizens could view on a smartphone app.

"In the past, science and technology mainly contributed to Korea's industrialization," says Kwon. "But as society becomes increasingly complex, science and technology are being used to resolve many societal issues."

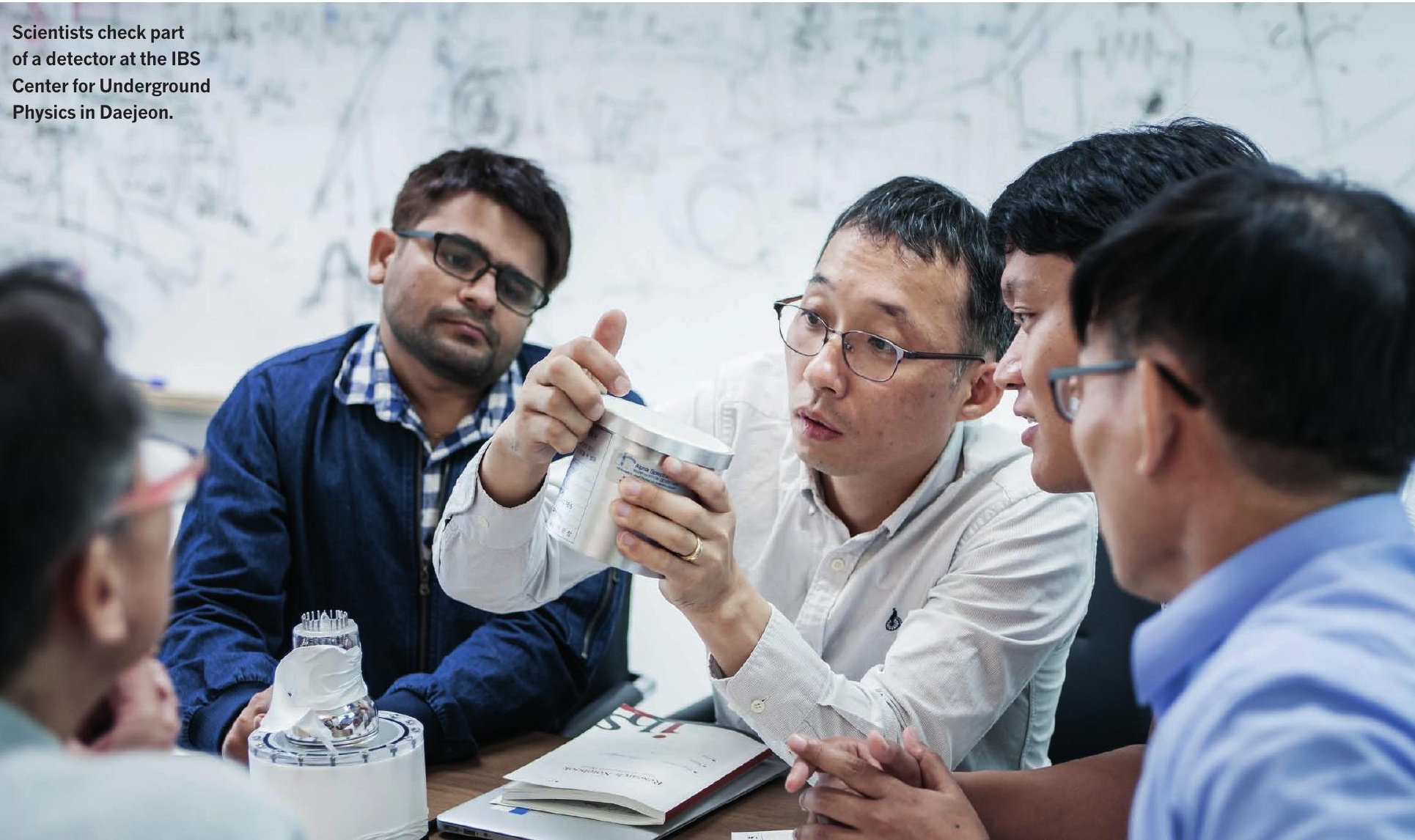




\section{TOP 10 INSTITUTIONS IN DAEJEON}

\begin{tabular}{|c|c|c|c|c|c|}
\hline RANK & INSTITUTION & WFC 2012 & WFC 2016 & $\begin{array}{c}\text { CHANGE IN WFC } \\
2012-2016\end{array}$ & AC 2016 \\
\hline 2 & Center for Theoretical Physics of the Universe, IBS & $\mathrm{n} / \mathrm{a}$ & 13.0 & $\mathrm{n} / \mathrm{a}$ & 39 \\
\hline 4 & Korea Research Institute of Chemical Technology & 7.3 & 7.6 & $5 \%$ & 22 \\
\hline 5 & Korea Astronomy and Space Science Institute & 5.0 & 7.1 & $42 \%$ & 275 \\
\hline 8 & Electronics and Telecommunications Research Institute & 8.1 & 6.6 & $-19 \%$ & 17 \\
\hline 9 & Korea Research Institute of Bioscience and Biotechnology & 9.3 & 5.8 & $-38 \%$ & 25 \\
\hline 10 & Korea Research Institute of Standards and Science & 8.5 & 5.2 & $-38 \%$ & 28 \\
\hline
\end{tabular}

\section{TOP 10 INSTITUTIONS IN SEOUL}

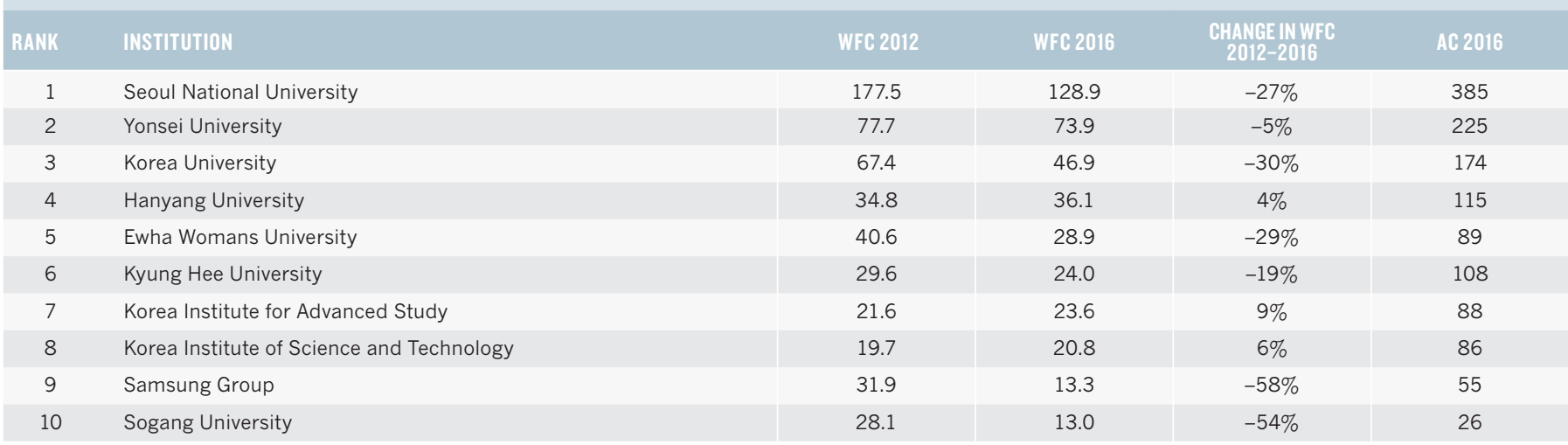

\section{TOP 10 COLLABORATIONS IN DAEJEON}

\begin{tabular}{|c|c|c|c|c|c|}
\hline RANK & INSTITUTION 1 & CS 1 & INSTITUTION 2 & CS2 & TOTAL CS \\
\hline 1 & University of Science and Technology & 5.61 & Korea Astronomy and Space Science Institute & 12.46 & 18.08 \\
\hline 2 & Chungnam National University & 1.68 & Korea Advanced Institute of Science and Technology & 4.01 & 5.68 \\
\hline 3 & University of Science and Technology & 1.76 & Korea Research Institute of Bioscience and Biotechnology & 3.69 & 5.44 \\
\hline 4 & Korea Advanced Institute of Science and Technology & 3.49 & Korea Basic Science Institute & 1.52 & 5.01 \\
\hline 5 & Chungnam National University & 1.64 & Korea Astronomy and Space Science Institute & 2.11 & 3.75 \\
\hline 6 & Korea Advanced Institute of Science and Technology & 2.55 & Korea Research Institute of Chemical Technology & 1.19 & 3.74 \\
\hline 7 & Korea Advanced Institute of Science and Technology & 2.13 & Korea Astronomy and Space Science Institute & 1.34 & 3.47 \\
\hline 8 & Korea Advanced Institute of Science and Technology & 2.19 & Electronics and Telecommunications Research Institute & 1.00 & 3.19 \\
\hline 9 & Korea Advanced Institute of Science and Technology & 1.59 & Korea Institute of Energy Research & 1.30 & 2.89 \\
\hline 10 & Korea Advanced Institute of Science and Technology & 2.50 & South Korea Agency for Defense Development & 0.38 & 2.88 \\
\hline
\end{tabular}

\section{TOP 10 COLLABORATIONS IN SEOUL}

\begin{tabular}{|c|c|c|c|c|c|}
\hline RANK & INSTITUTION 1 & CS 1 & INSTITUTION 2 & CS2 & TOTAL CS \\
\hline 2 & Seoul National University & 6.33 & Yonsei University & 5.64 & 11.97 \\
\hline 4 & Ewha Womans University & 2.11 & Seoul National University & 4.92 & 7.03 \\
\hline 5 & Seoul National University & 4.08 & Korea Institute of Science and Technology & 2.43 & 6.51 \\
\hline 6 & Yonsei University & 2.74 & Korea Institute of Science and Technology & 3.70 & 6.43 \\
\hline 8 & Korea University & 2.32 & Kyung Hee University & 2.77 & 5.09 \\
\hline 9 & Hanyang University & 2.75 & Seoul National University & 2.14 & 4.89 \\
\hline 10 & Kyung Hee University & 2.69 & Korea Institute of Science and Technology & 1.72 & 4.41 \\
\hline
\end{tabular}

